\title{
DIÁLOGOS COM MICHEL DE CERTEAU SOBRE PESQUISA NAS CIÊNCIAS HUMANAS
}

\section{DIALOGUES WITH MICHEL DE CERTEAU ON RESEARCH IN SCIENCES HUMAN BEINGS}

Francisco das Chagas de Loiola Sousa*

\begin{abstract}
Resumo
A proposta deste artigo é estabelecer um diálogo com Michel de Certeau sobre o trabalho do pesquisador no campo da História e das Ciências Humanas, em geral. Para tal intento, a sua obra, A escrita da História, é referência para esta reflexão. Os procedimentos teóricos e metodológicos das investigações nas Ciências Humanas, especialmente na área da História, são aqui analisados. A este respeito, o presente trabalho privilegia a análise do modo de produção do conhecimento científico adotado nas academias pelos grupos de pesquisa. Além disso, discutiremos alguns dos aspectos da vida acadêmica, como, por exemplo, as regras oficiais e as não-ditas que regem a vida dos pesquisadores nas instituições superiores de ensino e pesquisa.
\end{abstract}

Palavras-chave: conhecimento científico, pesquisa e instituição.

\section{Abstract}

The purpose of this paper is to establish a dialogue with Michel de Certeau on the work of researcher in the field of history and the humanities in general. For this purpose, his work, The Writing of History, is a reference for this discussion. The theoretical and methodological procedures of research in the Humanities, especially in the area of history, are reviewed here. In this regard, this paper focuses on the analysis of the production of scientific knowledge in the academies adopted by research groups. Furthermore, we discuss some academic aspects, for instance, the official and not official rules which regulate the practices of researchers under universities.

Keywords: scientific knowledge, research and institution

\section{INTRODUÇÃO}

O nosso diálogo com Michel de Certeau tem como referência A escrita da História $(1982)^{1}$, obra fundamental não só para os historiadores, mas também para os pesquisadores das Ciências Humanas em geral. A abordagem de Certeau sobre as perspectivas teóricas e os procedimentos metodológicos das investigações historiográficas modernas traz para 0 debate atual questões que sugerem certas revisões e/ou reflexões no modo de produção do conhecimento adotado nas academias.

Para Certeau, os métodos investigativos, dos últimos três ou quatro séculos, não cobrem a espessura nem a extensão do real. Neste sentido, boa parte do material coletado era descartado pelo pesquisador por extrapolar os limites teóricos das suas propostas de pesquisa. Contudo, estes "resíduos" ou conteúdos "descartados" tendem a ganhar, atualmente, novos

\footnotetext{
É professor da Universidade Federal de Campina Grande, Campus de Cajazeiras/PB, nas áreas de Filosofia da Educação e de Política Educacional. É graduado em Pedagogia, mestre e doutor em Educação pela Universidade Federal do Ceará. Desenvolve, atualmente, pesquisa sobre a história do magistério no ensino superior. E-mail: fcloiola@yahoo.com.br

1 Essa obra de Michel de Certeau foi publicada originalmente, em 1975, na França pelas Éditions Gallimard com o título L'Écriture de l'Histoire.
} 
significados com os procedimentos da narrativa historiográfica. Assim, o trabalho de contar, relatar e interrogar os acontecimentos ganha mais liberdade com as narrativas, o que proporciona também maior dignidade aos documentos e aos mortos, ou seja, às memórias dos sujeitos eleitos para compor o quadro de análise na investigação.

Nessa operação historiográfica, que está limitada à capacidade de análise do objeto em questão, exige-se do pesquisador a percepção das relações entre um lugar, eleito na proposta de pesquisa, os procedimentos adotados nas análises e a elaboração de um texto, que implica em diálogos com a literatura produzida pelo grupo de estudo ao qual o projeto de pesquisa está institucionalmente vinculado. Nesses grupos ou escolas de pesquisadores, existem as leis do meio acadêmico, o não-dito, que tem tanto poder de decisão quanto as regras oficiais publicizadas pelas instituições ou academias de pesquisas.

Essas escolas de pesquisadores produzem e publicam um tipo específico de saber partilhado por seus pares com uma linguagem científica própria. É a lei de um grupo que estabelece a lei de uma pesquisa científica. Em certa medida, esta lei define o que é permitido e o que é proibido no espaço acadêmico. As ideias produzidas nos grupos de pesquisa, desse modo, controlam os saberes que circulam na sociedade, o que implica também em "formatar" ideologicamente esta mesma sociedade.

Para uma reflexão mais detida sobre essas questões, tomaremos como referência para o diálogo com Certeau A escrita da História, principalmente o segundo capítulo porque nele 0 autor condensa reflexões teóricas e metodológicas importantes não só para o campo da historiografia, mas para a área das Ciências Humanas.

Desde já, alertamos aos leitores que outros temas, igualmente importantes para 0 historiador/pesquisador, presentes nesta obra de Certeau, não serão tratados aqui pelos próprios limites deste artigo. Além disso, consideramos que a riqueza da reflexão do referido capítulo é suficientemente relevante para se fazer merecedora de uma discussão-reflexão à parte, o que justifica a presente produção.

\section{A formação de grupos, o pesquisador e a pesquisa}

A produção do conhecimento científico é compreendida aqui como a produção do e no espaço-tempo das instituições, que agregam, por sua vez, os grupos de pesquisa das mais diferentes vertentes de pensamento. Os pesquisadores, iniciantes ou experientes, se agrupam de acordo com as afinidades teóricas e metodológicas. Assim, para pertencer a um determinado grupo de pesquisa é preciso estar vinculado às indicações teóricas e metodológicas de seus pares, os quais definem/distinguem os "bons" e "maus" métodos de pesquisa. Essa 
definição/distinção é uma forma de manifestação de poder nas academias. Desse modo, criamse e reproduzem-se as disputas de poder entre as diversas correntes do pensamento na busca de legitimidade científica, social e política das suas produções.

A esse respeito, a nova concepção de verdade da Ciência contemporânea contribuiu diretamente para consolidar o poder dos grupos de pesquisa nas academias. Com 0 enfraquecimento das concepções positivistas de verdade, o conceito de verdade absoluta tem sido substituído cada vez mais pelo conceito de verdade provisória. Para Jürgem Habermas (1988), o pesquisador não pode mais produzir conhecimento "sozinho", isolado do grupo, de modo que ele não pode afirmar que algo é verdadeiro ou válido sem o aval do grupo de estudos, do especialista, que é autoridade na sua área de investigação. Qualquer pretensão de validez do conhecimento científico tem, obrigatoriamente, de se submeter à crítica de seus pares. Desse modo, não é mais o pesquisador "solitário" quem define o que é e o que não é verdadeiramente válido, mas o grupo de estudo e os intelectuais de cada área do conhecimento.

Assim, os métodos de pesquisa adotados e modelos acadêmicos instituídos, a exemplo do Brasil, esboça um comportamento que se torna regras de acesso aos códigos acadêmicos, fundamentais para o sucesso na carreira de pesquisador e/ou professor universitário. Essas regras ou as leis do meio, instituídas no espaço acadêmico, definem o que é permitido e o que é proibido. São, assim, as permissões e as interdições, como assinala Foucault (1968), que permitem compreender a Ciência e suas relações de poder, que impedem a produção de uma historiografia mais autônoma.

\section{A transformação da natureza em cultura nas produções acadêmicas}

A prática historiográfica implica em um trabalho de transformar documentos, dados, vestígios em cultura. Para tanto, Certeau rejeita a ideia de que a história se reduz ao exercício de práticas e de técnicas, isso para afirmar que a capacidade de interpretar as fontes é indispensável. Assim, o trabalho do pesquisador consiste, sobretudo, em transformar o dado, 0 documento (a natureza) em texto escrito (a cultura), o que vai exigir uma formação à priori, uma boa dose de erudição do pesquisador. Esse tipo de trabalho é um processo no qual se artificializa a natureza, incluindo aí a natureza humana que vai modificando conforme se estabelecem conexões entre a socialização da natureza e a materialização e/ou "naturalização" das relações sociais.

O trabalho do pesquisador, nesse processo de artificializar a natureza, muitas vezes repercute numa dimensão exponencial. Um exemplo disso é o fato de que o dado encontrado pelo pesquisador pode tanto ser uma vasta documentação como um pequeno fragmento que, à 
primeira vista, é tomado como objeto sem aparente valor. Com o trabalho da escrita, quando bem estruturada, pode transformar esse pequeno fragmento em algo muito mais valioso do que se o pesquisador tivesse em mãos uma vasta documentação.

As informações primárias coletadas (matérias-primas), ao serem transformadas pelas mãos do pesquisador em informações secundárias, ganham um novo status social e científico. Essa nova condição implica em transportar coleções, arquivos, acervos, monumentos, etc., do campo da cultura para o campo da história. A este respeito, a natureza de um monumento pode ser modificada pela obra de historiadores: uma igreja, por exemplo, poder ganhar o status de museu.

O trabalho do historiador, desse modo, não se limita a produzir documentos, textos em uma nova linguagem. Isso ocorre porque no seu fazer pesquisa há um diálogo constante do presente com o passado, e o produto desse diálogo consiste na transformação de objetos naturais em cultura. Ou seja, o historiador incorpora a natureza à civilização.

\section{As fontes e a sua redistribuição no espaço e no tempo}

Ao recolher documentos, de acordo com os objetivos do seu projeto de pesquisa, o historiador desloca esse material no tempo e no espaço. O trabalho de fotografar, de transcrever, de microfilmar, enfim, de transportar as fontes de um lugar para outro, adequando-as aos objetivos do pesquisador, propostos a priori, implica numa tarefa que separa, recorta, isola, etc., os documentos do conjunto no qual foi originalmente produzido. Essa operação técnica, além de conter as impressões e/ou o olhar do pesquisador, transforma os documentos, fragmenta-os para se adequar à lógica do projeto de pesquisa proposto antes de iniciar a recolha dos dados. À medida que os dados coletados não se "encaixam" àquela lógica, quase sempre estes são excluídos dos resultados da investigação. Para garantir a validade de seu estudo, e convencer seus pares da relevância social e científica da pesquisa, os pesquisadores que trabalham com este tipo de fonte criam uma linguagem que dê unidade textual (lógica) e estabeleça um diálogo com as fontes, tendo sempre como referência a matriz teórica e metodológica na qual está filiado. Esta matriz o autoriza socialmente e cientificamente como sábio e autoridade na sua área de pesquisa, uma referência para pesquisadores inexperientes ou iniciantes.

Nesta perspectiva, os arquivos, incluindo as bibliotecas, são por excelência os lugares da erudição, lócus de um saber erudito, que permite aos pesquisadores acessarem, ao mesmo tempo, às fontes pelas quais se produzem novos conhecimentos e, ao mesmo tempo, aos saberes produzido pela Ciência. Essa condição dos arquivos se deve, sobretudo, ao seu novo status social, originado principalmente com as mudanças tecnológicas que permitem novas 
formas de fazer pesquisa. As práticas de copiar, classificar, imprimir, etc. documentos nos arquivos modernos redefinem a própria condição do saber. 0 impacto dessas mudanças tecnológicas nas pesquisas, com o uso de novas técnicas e equipamentos, a exemplo dos computadores, possibilitam outras formas de lidar com as fontes. Tais transformações implicam na adoção de diferentes posturas do pesquisador, as quais vão, em certa medida, depender dos meios tecnológicos utilizados por ele para acessar às fontes. Assim, os procedimentos investigativos também serão redimensionados em face das novas técnicas e equipamentos disponíveis.

Quando o assunto é tecnologia, a tendência é sempre enxergar as suas vantagens, uma vez que elas facilitam as trocas de informações entre pesquisadores e ampliam em escala planetária, por meio da internet, o acesso aos conhecimentos produzidos nas academias. Um exemplo de desvantagem dessa tecnologia é a facilidade com que se descartam informações importantes, como mensagens eletrônicas que são, quase sempre, deletadas, e as fontes de pesquisa dessa natureza tendem a se reduzir consideravelmente ou mesmo a desaparecer em um futuro próximo. Assim, a troca de mensagens via texto eletrônico, embora facilite a nossa vida pela economia de trabalho e de tempo, não deixa rastro, registro sobre nossa vida para as sociedades presente e futura. As trocas de cartas entre amigos, parentes, etc., por exemplo, que são valiosas fontes de investigação atualmente, deixam de ser, a partir de então, uma possibilidade de conhecimento sobre a sociedade contemporânea e futura. Este é um dos custos que pagamos pelas facilidades dos meios de comunicação.

\section{Os métodos investigativos e o estabelecimento de limites para a pesquisa e o pesquisador}

O modo de fazer pesquisa inspirado no positivismo valoriza a quantidade de informações acumuladas pelo pesquisador, embora essas informações sejam recolhidas em número limitado. Tal concepção tem como fundamento principal o método indutivo, de Francis Bacon (1561 1627), que é considerado um dos primeiros filósofos da Ciência Moderna. Seu projeto científico ou método indutivo, nomeado de empirismo, influenciou as gerações que o sucederam. Ele acreditava que, com certo número de informações recolhidas dos objetos investigados, 0 pesquisador poderia isolar do conjunto de dados colhidos aspectos que se repetiam em cada objeto observado ou submetido aos experimentos científicos. 0 resultado final da pesquisa jamais poderia ser originado de ideias preconcebidas pelo cientista, uma vez que 0 conhecimento científico é extraído do próprio objeto investigado, pois nessa concepção 0 conhecimento sobre o objeto está no próprio objeto. Dessa forma, as ideias do pesquisador não 
poderiam determinar ou influenciar os resultados da sua investigação (Bacon, 1984).

Com essa concepção de pesquisa, as informações reunidas são limitadas porque se faz necessário excluir as diversidades, ou seja, o que não se repetia com frequência nos experimentos, para dar uniformidade e coerência ao relatório de pesquisa. Quando ocorria algo inesperado, como a presença de elementos novos produzidos por outras investigações, a pesquisa estava, de certo modo, sujeita ao fracasso. Como estratégia para salvar a tese defendida, o pesquisador prosseguia na coleta de dados empíricos na tentativa de encontrar alguma novidade que justificasse cientificamente a relevância da pesquisa. A tarefa de reunir as informações necessárias para atingir este objetivo, por vezes, se prolongava demasiadamente e tornava-se um trabalho interminável. Caso o pesquisador não encontrasse alguma novidade relevante nessa nova coleta de dados, o trabalho final da pesquisa poderia estar condenado à caducidade e ao fracasso científico.

Na perspectiva de pesquisa contemporânea, essa lógica positivista de investigação tem sido cada vez mais abandonada pelos pesquisadores das Ciências Sociais, da Educação, bem como das Humanidades em geral. O trabalho de isolar, selecionar, recortar traços significantes, que se repetem com certa frequência na documentação consultada, é cada vez mais substituído por abordagens que incorporam o que antes eram considerados como "desvios" nas lógicas positivistas. Por apresentar "incoerências", esses "restos" do passado eram excluídos nas combinações lógicas dos relatórios de pesquisa. Assim, temas considerados marginais, a exemplo da feitiçaria, da loucura, da literatura popular, relegados ao silêncio, agora ganham lugar de destaque nas pesquisas.

Tal mudança de perspectiva nas investigações se deve ao fato de que o pesquisador não aspira, como antes, a uma abordagem universal. As pesquisas, embora privilegiem certos objetos com características particulares, não deixam de estabelecer conexões com as totalidades, com os contextos tempo-espaço e, em certa medida, com as estruturas sociais, econômicas, políticas, jurídicas, culturais e religiosas.

0 pesquisador contemporâneo, ao se interessar por questões historicamente marginalizadas pela Ciência, amplia o seu repertório de fontes e sujeitos. Essa ampliação, em parte, se deve ao desenvolvimento da tecnologia, como é ocaso do computador e seus artefatos (as escaneadoras, as máquinas fotográficas, etc.) ${ }^{2}$, que permitem recolher e armazenar dados

2 Com o uso do computador, a quantidade de documentos não é um fator determinante na pesquisa. A capacitada das novas máquinas armazenarem fontes de natureza diversas torna indeterminado o número de dados utilizados pelo pesquisador. Além disso, os dados "qualitativos" podem ser combinados com os "quantitativos" tornando imprecisa a quantidade de dados. Assim, as fronteiras das investigações mudam consideravelmente. 
de diversas natureza. Mesmo nos casos em que não temos acesso a documentos (por extravio, por impedimento oficial ou mesmo por impedimento de particulares) para realizar uma investigação, o pesquisador recorre, quando é possível, ao recurso da entrevista.

As entrevistas, como fonte oral, proporcionam um tipo de evidência específica que, se bem conduzidas, podem render bons resultados às pesquisas. Esse tipo de fonte se torna interessante porque tanto pode esclarecer interrogações sobre determinados eventos históricos, preencher lacunas de outros documentos, etc. quanto aguçar a curiosidade do pesquisador e pode levá-lo a outras fontes. Neste caso, é imprescindível para o pesquisador o auxílio de documentos:

para indicações de coisas que estão além do alcance da memória, para datas onde possam haver erros e para precisões que não poderá ou não irá conseguir com evidência oral. Ele precisará dos documentos para enriquecer e informar seu questionamento, para permitir aos mortos falarem aos vivos e, aos vivos, falarem aos mortos. (Samuel, 1990, p.237).

As reminiscências sobre determinados períodos históricos são importantes para (re) compor, a partir de uma versão narrada pelas próprias personagens da história, o seu quadro de análise com base em registro "subjetivo" (Thompson, 1992). O pesquisador, porém, deve tomar alguns cuidados específicos com o manuseio de documentos produzidos com as entrevistas. Em primeiro lugar, devemos ter consciência de que as histórias narradas, em geral, tendem a demonstrar o passado de acordo com o que pensamos no presente e o que pretendemos ser, pois "não são representações exatas de nosso passado, mas trazem aspectos desse passado e os moldam para que se ajustem às nossas identidades e aspirações atuais". (Thomson, 1997, p.57).

Tais considerações são importantes porque nos chamam atenção para o fato de que, ao lidarmos com o passado, sempre procuramos interpretá-lo com o olhar de hoje. Assim, por mais que procuremos nos aproximar do passado, tendo em mente preservar os significados originais das idéias e dos contextos políticos específicos de cada época, o pesquisador jamais poderá se isentar dos paradigmas contemporâneos em suas investigações. $O$ que de fato ele pode e deve fazer é procurar amenizar as influências desses paradigmas na leitura do passado, que exigirá do pesquisador uma boa dose de erudição e consciência histórica (Jasmin, 2005).

Essa condição temporal do informante e da testemunha da história, bem como do próprio pesquisador, redimensiona a percepção do problema em questão. A distância temporal, neste caso, nos impõe olhar diferente sobre os fenômenos sociais de determinada época. Esses cuidados, porém, não tornam menos importante ou menos válido o testemunho oral como fonte de pesquisa histórica, o qual contribui para dar voz e visibilidade às experiências de vida 
excluídas, quase sempre, das narrativas historiográficas ou pouco valorizadas por elas.

\section{Os procedimentos teóricos e metodológicos, as regras do meio acadêmico e os limites do texto científico}

No passado, a ciência positivista descartava uma quantidade considerável do material recolhido para a análise do fenômeno investigado, que, de acordo com o objetivo da pesquisa, esse material poderia ser proporcionalmente superior ao que era utilizado na pesquisa. Essa prática de excluir do relatório de pesquisa o "excesso" de material recolhido ou mesmo produzidos pelo pesquisador, como é o caso das entrevistas, continua nas tendências póspositivistas, com ênfase nas pesquisas do tipo qualitativa. Tal dificuldade se deve, em parte, ao fato de que, grosso modo, os objetivos das pesquisas são definidos previamente nos projetos de pesquisa sem que, muitas vezes, leve em consideração as fontes com as quais irá trabalhar. Isto, por vezes, produz desencontros entre os procedimentos teóricos e metodológicos e as fontes utilizadas na pesquisa. Nessa lógica, o olhar do pesquisador, quando vai realizar a coleta de dados, está, de certo modo, condicionado pela orientação teórica e metodológica do seu projeto de pesquisa.

Esse impasse entre o que pode ser explicado/compreendido pelo pesquisador e o que é considerado inexplicável pela teoria adotada por este, põe indagações do tipo: quais os limites dos procedimentos teóricos e metodológicos adotados para lidar com as fontes privilegiadas na nossa pesquisa? Como o modo de fazer ciência limita a compreensão do passado? É possível nos transportar para um determinado lugar do passado e perceber a espessura dessa realidade utilizando apenas documentos produzidos pela tradição escrita? Qual a validade científica do que nós produzimos? Podemos entender ou mesmo analisar um período da nossa história com base em "fragmentos" de documentos? Quais os limites e possibilidades de ultrapassar as fronteiras ou leis estabelecidas pelo saber científico contemporâneo?

As indagações, elaboradas anteriormente, têm a pretensão de aguçar a curiosidade e estimular o pensamento crítico e criativo, e não exatamente dar conta de toda a complexidade que envolve tais questionamentos. As perguntas, muitas vezes, são mais interessantes para a reflexão do que, propriamente, os comentários limitados ou mesmo aqueles que limitam a nossa capacidade de percepção do passado. Assim, uma interrogação que possibilite ir além dos saberes construídos pela Ciência moderna pode ser mais interessante do que uma tentativa de resposta ou comentários sobre 0 assunto em pauta.

A esse respeito, as experiências de pesquisa podem suscitar interrogações valiosas quando da conclusão de uma etapa de investigação. Os caminhos perseguidos pelos 
pesquisadores, quando permitem novas indagações sobre o objeto em questão, criam possibilidades de renovar o olhar sobre "antigas" abordagens. Neste sentido, a reorganização do passado pelo formato da nova escrita, do novo olhar, produz outros significados a respeito de uma mesma realidade que já foi investigada por outros pesquisadores.

Só o fato de elaborar novos texto e (re) organizar o pensamento e/ou a sua forma de exposição (porque cada texto tem seus limites de alcance) por si só já transforma a matriz anterior, que servia de referência para pensar determinadas abordagens. Assim, temas bastante explorado no meio acadêmico podem ganhar outros olhares, outras percepções. Geralmente 0 que conta é, em especial, a capacidade de reflexão, ou seja, a experiência e o conhecimento do pesquisador na sua área de atuação.

Nesta perspectivas, a pesquisa como possibilidade infinita de reflexão (a pesquisa não tem fim!) se constitui em um instrumento de ampliação do conhecimento e, ao mesmo tempo, de garantir a sua renovação. A prática de pesquisa exige uma teoria, que é necessária para formular questionamentos e/ou críticas sobre o conhecimento produzido em cada área do conhecimento. Essa teoria deve estar, de certo modo, adequada ao tema abordado e, consequentemente, aos objetivos pretendidos na pesquisa. Nesse sentido, a ausência desse suporte teórico tende muito mais a reproduzir do que, propriamente, a renovar o conhecimento científico, o que implica na (re) produção de saberes dogmáticos que eternizam conceitos, valores e olhares sobre determinadas abordagens do passado.

Do ponto de vista dos procedimentos, a teoria permite a compreensão das fontes - e do objeto de investigação - para além dos seus significados particulares. Ela possibilita diálogos com outros elementos do espaço social no qual a investigação ocorre. Assim, a operação historiográfica tenta compreender as possíveis relações entre um objeto de investigação, a teoria e seus procedimentos de análises e as produções literárias do campo epistemológico ao qual a pesquisa está vinculada.

Contudo, a escrita de um texto científico, a exemplo de um relatório ou projeto de pesquisa, é elaborado de acordo com as regras da instituição, da academia, o que limita a autonomia do pesquisador. Cada área de conhecimento se constitui de especialistas, de grupos ou equipes de pesquisa, de líderes desses grupos, etc. Os cursos de pós-graduação nas universidades (especialização, mestrado e doutorado) são exemplos de formação desses grupos. Assim, elaborar um projeto de pesquisa para esses cursos vai exigir do pesquisador certos conhecimentos prévios da instituição e do grupo de pesquisadores ao qual pretende se vincular. Tais conhecimentos prévios vão além dos critérios formais (textuais) de seleção dos projetos. É necessário, sobretudo, conhecer as regras não-ditas que, por vezes, determinam a 
escolha de um e não de outros projetos. Conhecer a literatura com a qual o grupo trabalha é um bom começo. Desse modo, o grupo de pesquisadores tende a aceitar um tipo de produção escrita, definida como padrão desse grupo, e interditar outras formas de escrita, consideradas fora do padrão. Assim, prevalece a lei de um grupo, que é a lei de uma pesquisa científica.

Tais grupos de pesquisadores se constituem como uma sociedade de estudos com autoridade na sua área de investigação. Para tanto, usam uma linguagem comum ao grupo, que padroniza as publicações nas revistas especializadas. Assim, as leis do meio acadêmico, nãoditas, sustentam um discurso, que é o discurso do grupo, pois é o grupo quem produz conhecimento científico, e não o sujeito, o indivíduo solitário. Assim, prevalece o nós em detrimento do sujeito, do pesquisador solitário. Nesse meio qualquer escrita necessita do aval do grupo (do outro) para se afirmar como discurso válido, certificado. Há uma espécie de contrato social, não-dito, entre os membros do grupo. Contudo, a formação dos grupos de pesquisadores, no caso brasileiro, nem sempre é pacífica. Os conflitos, por vezes, criam malestar entre os membros dos grupos de pesquisa quando há disputa de legitimidade teórica, e, ao mesmo tempo, de poder.

\section{A inversão escrituraria: da proposta de investigação à elaboração do relatório de pesquisa}

$\mathrm{Na}$ elaboração do texto ou relatório de pesquisa há uma transformação no estilo da escrita, que Certeau denomina de inversão escrituraria. Segundo ele, o que ocorre entre a execução das propostas de pesquisa e a construção das monografias, dissertações e teses, bem como a produção de artigos e livros, é a inversão dos percursos escriturário. A escrita do texto, neste sentido segue um caminho inverso ao da investigação, ou seja, ao do momento da recolha e sistematização das fontes de pesquisa.

Ao iniciar um texto, artigo ou livro, por exemplo, logo na introdução é perceptível àquela inversão. As teorias (reflexões mais abstratas) construídas com base nos insight percebidos no final do trabalho de campo são logo anunciadas na introdução do texto. As novidades percebidas durante a recolha dos dados, no final do trabalho de campo, ganham maior destaque no início da exposição por serem consideradas importante contribuição do pesquisador para o grupo de pesquisa e a instituição a que se vincula.

Desse modo, o percurso da escrita do texto segue um caminho cronológico inverso ao do trabalho de campo e organização das informações recolhidas. Assim, o texto do relatório de pesquisa, transformado em artigos, livros, etc., ganha um formato diferente da prática de investigação. Esta, por não estabelecer limites para o seu término, persegue toda a vida do 
pesquisador. O texto, por sua vez, obrigatoriamente deve estabelecer limites de alcance da reflexão, a qual estará condicionada ao formato científico padronizado pelo veículo de publicação do meio acadêmico, a exemplo das revistas indexadas.

No caso do Brasil, as exigências dos grupos e das instituições para que os pesquisadores publiquem suas pesquisas com certa frequência ${ }^{3}$ fazem com que, muitas vezes, sejam divulgados os resultados das pesquisas sem que, necessariamente, tais pesquisas tenham sido concluídas. A antecipação da divulgação dos resultados antes de concluir o trabalho de campo de uma etapa de investigação, seja em anais de congressos científicos ou mesmo em revistas científicas especializadas, implica numa mudança na ordem cronológica da exposição. Neste caso, diferentemente do que Certeau afirma, a inversão escrituraria se constitui apenas parcialmente, uma vez que a publicação das produções ocorre antes de concluir a coleta dos dados empíricos na sua totalidade. Isto faz sentido porque a continuidade da investigação pode revelar, desse modo, outros resultados diferentes daqueles apresentados anteriormente. A urgência em publicar as produções acadêmicas exige que as novidades encontradas sejam divulgadas na medida em que elas vão surgindo no percurso da pesquisa, o que impede 0 amadurecimento das reflexões teóricas e limita a possibilidade de debate, críticas, etc. entre seus pares antes da divulgação. Os prazos, quase sempre exíguos, para a conclusão das pesquisas também se constituem em empecilhos àquelas reflexões.

A escrita do texto, como organização de significantes, procura dar sentido ao que a prática investigativa percebe como limite, exceção ou diferença, elementos às vezes "soltos", que se apresentam aparentemente sem coesão nem coerência. As lacunas ou incoerências da pesquisa, especialmente na sua fase de coleta dos dados, são superadas pela construção do texto. Contudo, essa não é uma tarefa fácil, porque a história não tem sentido, e atribuir sentido à história exige do pesquisador certo domínio (conhecimento profundo) sobre os contextos nos quais se travam os conflitos sociais e as estratégias de resolução:

\footnotetext{
A história não tem "sentido", o que não quer dizer que seja absurda ou incoerente. Ao contrário, é inteligivel e deve poder ser analisada em seus pormenores detalhes, mas segundo a inteligibilidade das lutas, das estratégias, das táticas. Nem a dialética (como lógica de contradição), nem a semiótica (como estrutura de comunicação) não poderiam dar conta do que é a inteligibilidade intrínseca dos confrontos (Foucault, 1993, p.05).
}

A compreensão e análise do passado, bem como a atribuição de significado ao que aconteceu, vão depender do espaço-tempo (lugar e época) de onde "falo". O distanciamento

3 A CAPES, por exemplo, considera nas avaliações do desempenho dos cursos de pós-graduação Stricto Sensu ou para a criação destes cursos, apenas o que o pesquisador publicou nos três últimos anos. 
temporal, por exemplo, muda a compreensão e a relação do pesquisador e dos sujeitos investigados sobre os acontecimentos; e o sentido do que aconteceu também muda com 0 tempo. Assim, o olhar sobre determinado fenômeno social no "calor" do acontecimento é diferente dos sentimentos futuros sobre este mesmo episódio.

\section{CONCLUSÃO}

As reflexões de Certeau sobre o trabalho do historiador, e suas relações com seus pares e as instituições a que está vinculado, ganham proporções para além de suas pretensões quando tais análises são também válidas para o conjunto de sujeitos que produzem conhecimento científico no campo das Ciências Humanas.

As contribuições de A escrita da história põem interrogações, e, ao mesmo tempo, revelam elementos inerentes às práticas de pesquisa que desnudam muitas das relações do pesquisador com o conhecimento produzido pela academia e com os lugares (sociais, políticos, econômicos e culturais). Estas e outras relações dão uma ideia das condições de produção do conhecimento no meio acadêmico, especialmente no que diz respeito às regras não-ditas que são tão determinantes para o sucesso ou o fracasso do pesquisador quanto àquelas prescritas oficialmente pelas instituições através e com os grupos de pesquisadores de cada área do conhecimento. Neste sentido, Certeau dedica boa parte de suas análises às práticas instituídas no meio acadêmico, as regras do meio, nas quais revela um sistema ético e técnico que opera com regras próprias instituídas pelos grupos. Tais regras, nem sempre explícitas, determinam o que pode e o que não pode, ou seja, o que é permitido e o que é proibido nos grupos e nas instituições para os quais se destinam o saber científico.

Os procedimentos investigativos, amparados por esse sistema ético e técnico, permitem fabricar textos e discursos sobre sujeitos, lugares, épocas, etc., que ganham autoridade e certificado acadêmico, ou seja, ganham validade social e científica. Neste aspecto o texto, sob o comando do pesquisador, ganha sentido particular (a história não tem sentido), atribuído pelo seu autor em acordo com o grupo. A construção do texto, graças às possibilidades semânticas da escrita e às teorias, dá uniformidade, coesão e coerência aos discursos dos intelectuais. Os materiais e/ou documentos reunidos durante o trabalho de campo, muitos deles aparentemente sem nexos, fragmentados ou mesmo apresentando contradições, são organizados no texto de tal modo que estas ausências ou silêncios presentes nas fontes de pesquisa são preenchidos de significados. Isto é possível porque o historiador, por exemplo, fabrica o sentido da história. Tais procedimentos de pesquisa possibilitam construir aspectos do passado a partir do que chegam aos dias atuais em forma de fragmentos ou mesmo apresentando contradições. Nesta 
perspectiva, por um lado, as narrativas emergem com maior possibilidade de compreender e analisar a espessura e a extensão do real; por outro, corre-se maior risco de (re) construir um passado mais fictício do que propriamente real. Isso pode acontecer no caso das fontes reunidas serem insuficientes para construir um sentido mais pragmático da história.

Além disso, o limite do texto científico, em face das regras do meio acadêmico, impõe ao pesquisador espaços circunscritos, de certo modo previamente definidos em acordo com 0 grupo, que condiciona a fluidez do pensamente inovador ou inibe a capacidade de buscar outros modos de explicar, compreender e analisar as fontes. A própria teoria adotada pelo grupo, como referência para análise de determinados objetos de investigação, por si só já antecipa algumas das conclusões da pesquisa antes mesmo do pesquisador chegar ao final do trabalho de campo e de concluir uma determinada etapa do estudo.

Para além desses condicionantes, o trabalho do pesquisador nas Ciências Humanas tem avançado na tentativa de ampliar o olhar sobre os objetos de pesquisa. As práticas investigativas dão cada vez mais atenção para os desvios, dados importantes da pesquisa que não se "encaixavam" no quadro ou esquema teórico e/ou metodológico da investigação. Esse material, excluído das análises, ganhou novo status científico ao ser incorporado ao trabalho acadêmico. Aqui ocorre, de certo modo, uma inversão em ralação ao que era privilegiado no modo de pesquisa adotado pelo positivismo. Os desvios ou exceções, que se afastam das regularidades, não cabiam nos sistemas explicativos dessa teoria.

Nos dias atuais, as dificuldades do pesquisador estão mais relacionadas a outra dimensão da investigação, que se refere ao problema de compreensão e análise do particular, do individual sem, contudo, submetê-lo ou relacioná-lo ao universal. Como generalizar objetos particulares, individuais, exclusivos? Como analisar determinado fenômeno social sem recorrer à teoria? Como indaga Certeau: "Como nomear o incompreendido?". Esse diálogo continua.

\section{REFERÊNCIAS}

1. BACON, Francis. Novum Organum ou Verdadeiras Indicações acerca da Interpretação da Natureza. Nova Atlântida. Tradução de Aluysio Reis de Andrade. São Paulo: Abril Cultural, 1984. Coleção Os Pensadores.

2. CERTEAU, Michel de. A escrita da História. - Tradução de Maria de Lourdes Menezes. Rio de Janeiro: Forense, 1982.

3. FOUCAULT, Michel. Doença mental e psicologia. Tradução de Lilian Rose Shalders Rio de Janeiro: Tempo Brasileiro, 1968. 
4. Microfísica do poder. $11^{\text {a }}$ edição - Tradução de Roberto Machado. Rio de Janeiro: Edições Graal, 1993.

5. HABERMAS, Jürgem. Teoria de la acción comunicativa: complementos y estúdios prévios. Tradução de Manuel J. Redondo. Madrid: Taurus, 1988.

6. JASMIN, Marcelo Gantus. História dos conceitos e teoria política e social: referências preliminares. Revista Brasileira de Ciências Sociais, V. 20, nº 57, São Paulo, p.27-38, fev./2005.

7. SAMUEL, Raphael. Documentação: história local e história oral. Tradução de Zena Winoma Eisenberg - Revista Brasileira de História. São Paulo, v.9, nº 19, p.219-243, fev./1990.

8. THOMPSON, Paul. A voz do passado: história oral. $2^{\mathrm{a}}$ edição - Tradução de Lólio Lourenço de Oliveira. Rio de Janeiro: Paz e Terra, 1992.

9. THOMSON, Alistair. Recompondo a memória: questões sobre a relação entre História Oral e as memórias. Revista Projeto História, São Paulo, n 15, p.51-71, abril/1997.

Artigo recebido em: 15/05/2010

Aprovado em: 18/06/2010 